\title{
The multiple faces of place branding in the EU: special issue on the fourth IPBA conference
}

\author{
Alex-Michael Deffner ${ }^{1}$ \\ Accepted: 5 October 2020 / Published online: 24 October 2020 \\ () Springer Nature Limited 2020
}

Conferences in general constitute an opportunity to meet colleagues, exchange ideas as well as follow the new research that is being conducted in the various fields. Due to the contemporary coronavirus effect, in the current phase conferences can take place only electronically, something that mainly affects the live communication between people. In this sense, written documents of conferences, such as proceedings or special journal issues, acquire additional importance in keeping the memory alive especially in the period between conferences of a particular association, department etc.

In the field of place branding the main world event is the Annual Conference of the International Place Branding Association, which in 2019 was organized by the Department of Planning and Regional Development of the University of Thessaly and took place in Volos, Greece at the end of November. The conference was generally considered to be a success, both in qualitative and quantitative terms. The presented papers were almost 100 and 22 full papers were submitted for the evaluation of the best conference paper award, as well as for the evaluation in order to be included in the current special issue. At the end of this process, five papers are included in the current special issue, mainly focusing on the attributes of the spatial level of branding implementation (supranational level and islands), on crucial factors for place identity (culture and heritage), and on new processes beyond residents' participation in place branding (co-creation).

The conceptual paper 'Towards a contemporary research agenda for island branding: developments, challenges, and dynamics' by Angeliki Mitropoulou and Ioannis Spilanis aims to reinforce research on alternative areas other than the cities, e.g. islands and insular areas. There are four main characteristics that seen in combination define insularity:

Alex-Michael Deffner

adeffner@uth.gr

1 University of Thessaly, Volos, Greece small size, remoteness and isolation, special experiential identity and particular, rich and vulnerable natural and cultural environment. This analysis is connected with the elaboration of a theoretical framework incorporating models like Hankinson's model about the development of mainstream and place branding domains (including origins such as urban policy, deepening such as destination branding, and widening such as services branding). There is an additional analysis of cross-disciplinary knowledge from other relevant fields focusing on the elaboration of a combination of concepts such as tourism, sustainable development, place branding and islandness. This conceptual approach does not constitute an aim in itself, but intends to identify place branding as a significant tool in the process of practicing contemporary public administration.

The enjoyable paper 'From poem and song to cultural diplomacy: challenges and opportunities for place branding and tourism promotion' by Christina Linardaki and Anastasia Aslanides makes a shift towards the contribution of art mainly arguing that poems and songs are cultural elements of place identity that can help in the rebranding process. Representative examples of Greek poetry and of Greek (or international) poetry set to music in particular are analyzed aiming at reconstructing the country's identity and image beyond the prevailing sun and sea model. This whole attempt is based in the attribute that poetry, and especially that set to music, offers a powerful cross-platform that enables communication among people, creating common understanding and bridging linguistic and cultural differences.

The paper 'Rebranding a "rather strange, definitely unique" city via co-creation with its residents' by Ulla Hakala, Arja Lemmetyinen and Lenita Nieminen goes beyond the usual approach of citizens' participation analyzing the more (pro)active concept of co-creation, focusing on its role in city rebranding. This is based on the fact that residents, by definition, i.e. because they live in the city, contribute largely to its placemaking. The case study is Pori in Finland, where the existing brand has not been documented 
and has been fragmented, since the administrative functions have acted independently, each implementing its own version of a brand. As a reaction to that, the aim of the cocreation process was to reform and reorganize Pori's brand in the direction of developing the city and its brand at a strategic level, without constructing a city make-over. The paper investigates and documents, using a rigorous methodology combining various qualitative methods and various sources of data, the co-creative rebranding process from initiation to implementation over a 5-year timeline. Five sequential stages in the co-creative rebranding process are identified: facilitating co-creation with residents, engaging residents in the co-creation, external evaluation, internal evaluation, and stimulating the dialogue with residents.

Ioulia Elmatzoglou's paper 'EU branding: Efforts to improve the EU image' got the Best Paper Award in the Conference and is related to supranational branding, a significant issue that has not been researched as much as it should. It seems that the negative occurrence of a series of crises such as economic, migration and Brexit (the refugee and the COVID-19 crises could be added) had a positive effect in providing the necessary conditions for EU to enhance its image and reputation. However, a comparative analysis between nation and EU branding showed the particularities of the EU, which is a sui generis political entity and its distinctive characteristics deprive the Union of a clear and strong brand image and identity. There is a shift from communication campaigns focusing on clearly political issues such as EU citizenship, "EU public sphere" and a "common sense of belonging" to a more pragmatic "branding" strategy, which also helps EU to improve its communication. The new EU branding strategy was applied more systematically on the May 2019 European Parliament election campaign amidst heavy criticism of the EU and a polarized election campaign.
The cultural focus continues in the paper 'Spatial strategies as a place branding tool in the region of Ruhr' by Evangelos Asprogerakas and Kiki Mountanea. In this case, the subject is heritage, which constitutes a common marketing tool that relies on the presentation also of urban forms related to the past. Place identity is something that is usually related to culture, and the construction of a strong, recognizable, and thus attractive, place identity is closely linked to the process of effective spatial planning. A usual field for the landscape renewal maintaining a link with the past is the repackaging and re-use of historical structures and brownfields of previous urban development models. The particular case study is the Ruhr Valley, which is undergoing a restructuring process after the decline of the concentration of mining and steel industry since the 1970s, which had caused severe social and economic problems. The analytical emphasis for the construction of a new identity is given on the development of the Emscher Landshaftspark, developed in the 1990s, and on the way in which the old abandoned industrial facilities were used in the context of configuring this new identity. The final aim of this paper is to identify a typology of interventions: mild interventions utilizing the facilities mainly as monuments with the addition of catering/leisure activities, aggressive initiatives usually related to creative industries, and development of new infrastructures based on a real estate approach.

Publisher's Note Springer Nature remains neutral with regard to jurisdictional claims in published maps and institutional affiliations. 